\title{
Racial Disparities in Colorectal Carcinoma Incidence, Severity and Survival Times Over 10 Years: A Retrospective Single Center Study
}

\author{
Hafiz Muhammad Sharjeel Arshad ${ }^{\mathrm{a}, \mathrm{b}}$, Eula Tetangco ${ }^{\mathrm{a}}$, Natasha Shah ${ }^{\mathrm{a}}$, Christopher Kabir ${ }^{\mathrm{a}}$, \\ Hareth Raddawi ${ }^{\mathrm{a}}$
}

\begin{abstract}
Background: Colorectal cancer (CRC) is the third leading cause of cancer-related deaths in the United States. Although studies have been performed on malignancy behavior in African Americans and Caucasians, scant data are present on other minority racial groups.
\end{abstract}

Methods: A retrospective single center study was performed where 1,860 patient charts with a diagnosis of CRC from January 1, 2004 to December 31, 2014 were reviewed. Data collected on each patient included age, gender, ethnicity, primary site and histological stage at the time of diagnosis. Survival time over the course of 5 years was documented for patients from January 1, 2004 to December 31, 2009. Comparisons were made amongst different racial groups for the above mentioned factors.

Results: Study population consisted of $27.09 \%$ African Americans, $65.61 \%$ Caucasians, 3.86\% Hispanics, $0.54 \%$ South Asians, $1.03 \%$ Arabs, $0.54 \%$ Asians and $0.22 \%$ American Indians. Mean age of CRC presentation was found to be significantly different $(\mathrm{P}<0.05)$ between the three largest racial groups: 71 years for Caucasians, 69 years for African Americans, and 61 years for Hispanics. African Americans (27.09\%) and Hispanics (28.79\%) presented predominantly at stage IV in comparison to other racial groups. Caucasians presented predominantly at stage III $(24.84 \%)$. The rectum was the most common site of CRC across all racial groups with the exception of Asians, where sigmoid colon was the predominant site $(30 \%)$. Adenocarcinoma remained the predominant cancer type in all groups. Hispanics had relatively higher incidence rate of carcinoid tumor $(12.68 \%)$. Survival time analysis showed that Caucasians tend to have better survival probability over 5 years after initial diagnosis as compared to African Americans and Hispanic

Manuscript accepted for publication August 18, 2016

aDepartment of Internal Medicine, University of Illinois at Chicago/Advocate Christ Medical Center, 4440 W 95th Street, Oak Lawn, IL, USA

${ }^{b}$ Corresponding Author: Hafiz Muhammad Sharjeel Arshad, University of Illinois at Chicago/Advocate Christ Medical Center, No. 131, $4440 \mathrm{~W}$ 95th Street, Oak Lawn, IL 60453, USA. Email: Sharjeel_169@hotmail.com

doi: http://dx.doi.org/10.14740/jocmr2696w
$(\mathrm{P}<0.05)$

Conclusion: There is lack of studies performed on minority racial groups in North America. Our study highlighted some important clinical differences of CRC presentation in different racial groups which are not well studied and can be used to formulate future multi-center studies to assess disease behavior.

Keywords: Colorectal cancer; Race; Ethnicity; Survival time; Site of colorectal carcinoma; Type of colorectal cancer; Stage of colorectal carcinoma

\section{Introduction}

Colorectal cancer (CRC) is the third leading cause of cancerrelated mortality in the United States. It causes approximately $9 \%$ cancer-related deaths [1]. Factors associated with an increased risk of CRC include older age, family history of CRC, inflammatory bowel disease, obesity, physical inactivity, type 2 diabetes mellitus, alcohol consumption, smoking, and consuming a diet high in red and processed meat $[2,3]$. On the other hand, some of the factors associated with lower risk of $\mathrm{CRC}$ incidence include non-steroidal anti-inflammatory drug (NSAID) use, greater consumption of calcium, fiber, folate, and vitamin $\mathrm{D}[2,3]$.

Although implementation of screening colonoscopy recommendations for prevention of this cancer has reduced national colorectal carcinoma incidence rate, there continues to be a need for further research and advancements in preventing CRC. Racial differences are an important point of focus in reducing burden of CRC in the Unites States. Studies have focused largely on Caucasians and African Americans. According to the American Cancer Society, the incidence of CRC in African-American males is 63.8 per 100,000 , as compared to 50.9 per 100,000 in Caucasian males. Similarly, mortality rates in African-American males were higher at 29.4 per 100,000, as compared to Caucasian males at 19.2 per 100,000. AfricanAmerican females were also found to have higher incidence and mortality rates from CRC as compared to Caucasian females [4]. 
Table 1. Racial Variation in Study Population

\begin{tabular}{lll}
\hline Race & Number of patients & \% of total \\
\hline African American & 498 & 27.09 \\
Caucasian & 1206 & 65.61 \\
South Asian & 10 & 0.54 \\
Arabs & 19 & 1.03 \\
Mexican-Americans & 71 & 3.86 \\
Asians & 10 & 0.54 \\
American Indian & 4 & 0.22 \\
Hawaiian/Pacific Islander & 1 & 0.05 \\
Unknown & 19 & 1.03 \\
\hline
\end{tabular}

Multiple factors have been proposed to contribute towards this racial disparity. There has been a call to include race as a factor in national CRC screening guidelines, and to commence screening at an age earlier than 50 years in individuals of potentially higher-risk racial groups like African Americans [5]. Doubeni et al found that African Americans were more likely than Caucasians to have distant or un-staged tumors, and supported the American Cancer Society's findings that this population had a higher risk of death from CRC when compared to Caucasians [6].

Very few studies have been performed on behavior of $\mathrm{CRC}$ in North American minorities such as Hispanics, Arabs, and Asians, and how the disease process differs in these groups as compared to well-studied racial groups of African Ameri- cans and Caucasians. Investigations that explore behavior of $\mathrm{CRC}$ in other races may impart preliminary data on genetics and provide baseline information that can serve as basis for recommendations in individualized prevention and treatment of CRC.

\section{Materials and Methods}

We performed a retrospective single center study with review of 1,860 patient charts from January 1, 2004 to December 31, 2014 at Advocate Christ Medical Center, Oak Lawn, IL. Eligible patients were identified from electronic medical records if they had a first occurrence of biopsy proven colorectal carcinoma and were at least 18 years of age. Patients were excluded from study if they had recurrent CRC. Patient demographic information was obtained from Care Connection EMR which captures race and ethnicity data based on self-report at the time of registration in accordance with US Census definitions. To obtain further useful data, Asians were classified in South Asians, Arabs and Asians. Data collected on each patient included age in years at the time of diagnosis of CRC, stage of CRC at time of diagnosis (stage I-IV), and type of carcinoma. Overall differences between the racial groups were assessed by Chi-square and ANOVA testing, using a $\mathrm{P}<0.05$ as the threshold for significance. Kaplan-Meier estimation for groups was conducted to assess survival times over a 5-year follow-up period.

The protocol for this study was approved with waiver of informed consent by Advocate Christ Medical Center's Insti-

Average age (years) for first CRC diagnosis

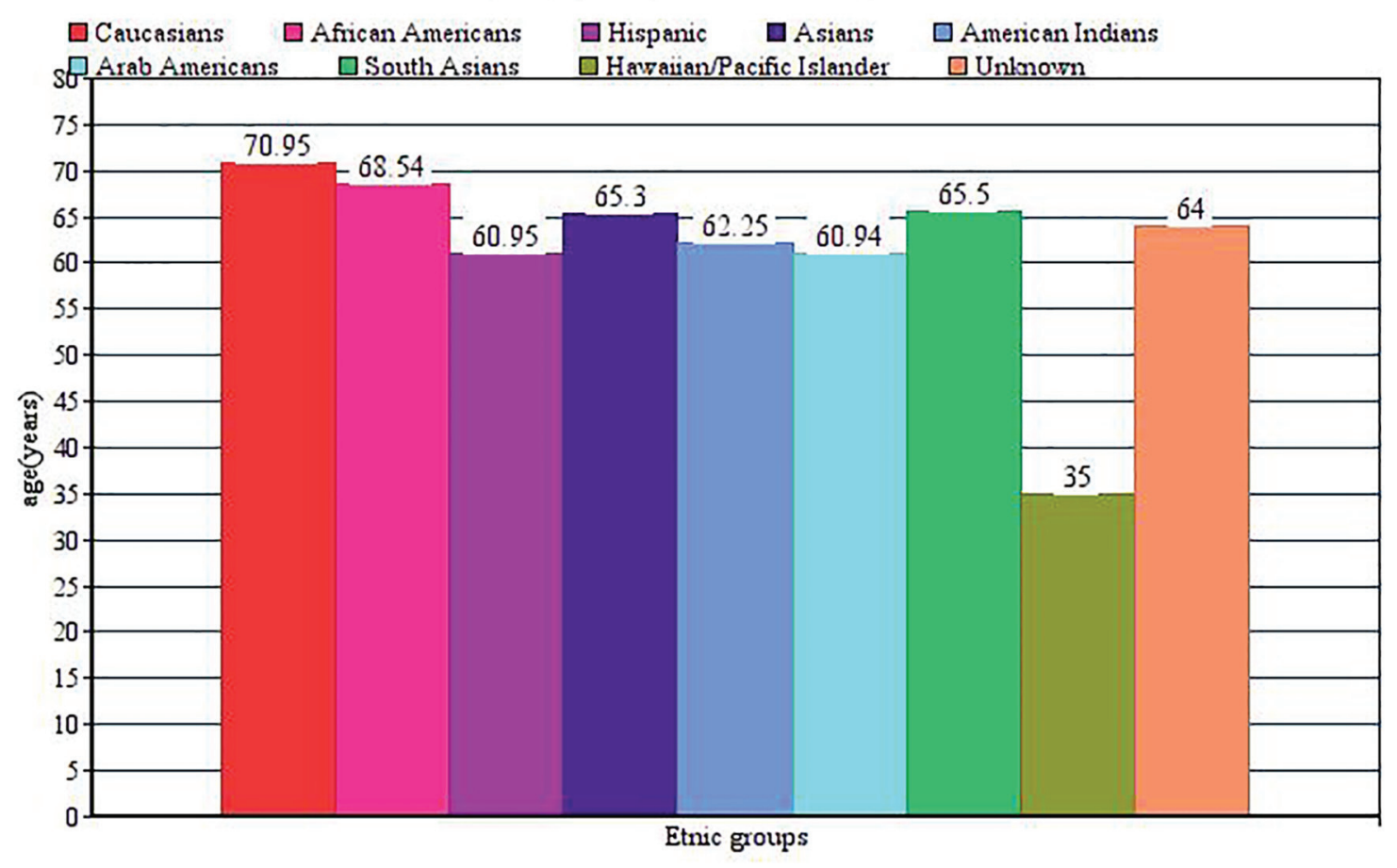

Figure 1. Mean age of CRC presentation for different ethnicities. 


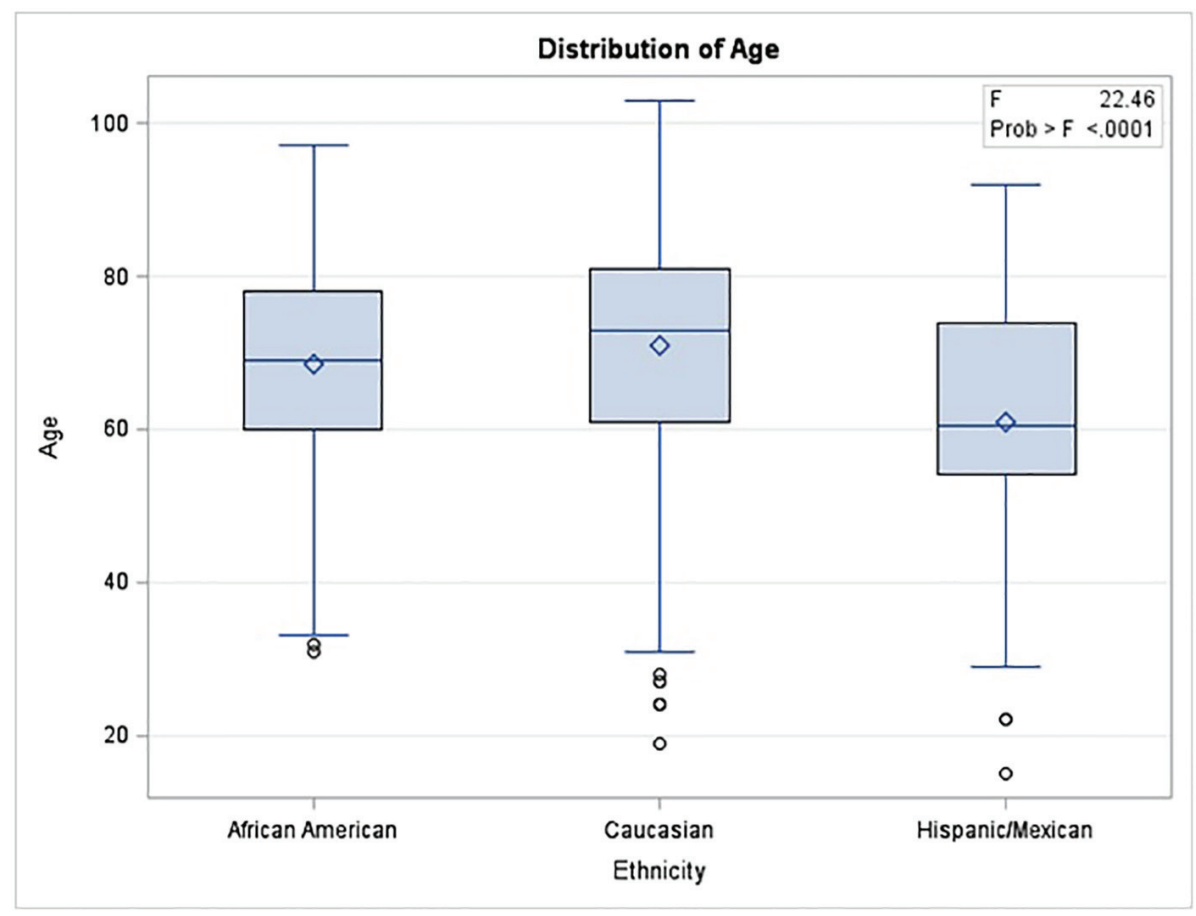

Figure 2. Distribution of age at presentation among major ethnic groups.

tutional Review Board. Statistical analysis was performed using SAS 9.4 (SAS Institute, Cary, NC).

\section{Results}

\section{Racial variations of study population}

Majority of patients were Caucasians and African Americans. A considerable number of Hispanic patients were also present in study population. Rest of ethnic minorities had very small presentation when compared with bigger ethnic groups (Table $1)$.

Study population consisted of $47.39 \%$ males and $52.61 \%$ females.

\section{Age at presentation}

Our results showed considerable variability across all racial groups. In particular, Hispanics presented with $\mathrm{CRC}$ at a much younger age as compared to African Americans and Caucasians. Mean age of CRC presentation was 71 years for Caucasians, 69 years for African Americans, and 61 years for Hispanics (Fig. 1). The mean comparison between these three racial groups was found to be statistically significant $(\mathrm{P}<0.05)$ (Fig. 2).

On further stratification of each racial group based on gender, we did not notice any statistically significant difference in most of the racial groups. Mean age of presentation was 68 years for African American males and 69 years for African
American females $(P=0.37)$. For Caucasians, it was 70 years in males and 72 years in females $(P=0.043)$. Mean age of presentation was 62 years in Hispanic males and 60 years in Hispanic females $(\mathrm{P}=0.598)$.

\section{Histological stage of CRC on presentation}

Following simplified table shows different racial groups with stages of CRC on initial presentation (Table 2).

As evident from above table, African Americans and Hispanics presented predominantly at stage IV (27\% and $28.7 \%)$ as compared to Caucasians (16.5\%) (Fig. 3). South Asians and Arabs presented predominantly at stage II (33.3\% and 50\%), while American Indians presented predominantly at stage I $(50 \%)$.

Table 2. Histological Stage of CRC at Diagnosis for Different Racial Groups

\begin{tabular}{llllll}
\hline \multirow{2}{*}{ Race } & \multicolumn{5}{c}{ Stage of CRC (\% within racial group) } \\
\cline { 2 - 6 } & $\mathbf{0}$ & $\mathbf{1}$ & $\mathbf{2}$ & $\mathbf{3}$ & $\mathbf{4}$ \\
\hline Caucasian & $12.3 \%$ & $22.6 \%$ & $23.6 \%$ & $24.8 \%$ & $16.5 \%$ \\
African American & $13.0 \%$ & $19.1 \%$ & $20.5 \%$ & $20.0 \%$ & $27.0 \%$ \\
Hispanic & $18.1 \%$ & $19.7 \%$ & $19.7 \%$ & $13.6 \%$ & $28.7 \%$ \\
South Asian & $11.1 \%$ & $11.1 \%$ & $33.3 \%$ & $33.3 \%$ & $11.1 \%$ \\
Arabs & $11.1 \%$ & $16.6 \%$ & $50.0 \%$ & $11.1 \%$ & $11.1 \%$ \\
American Indians & $0.0 \%$ & $50.0 \%$ & $25.0 \%$ & $0.0 \%$ & $25.0 \%$ \\
Asian & $33.3 \%$ & $0.0 \%$ & $11.1 \%$ & $22.2 \%$ & $33.3 \%$ \\
\hline
\end{tabular}




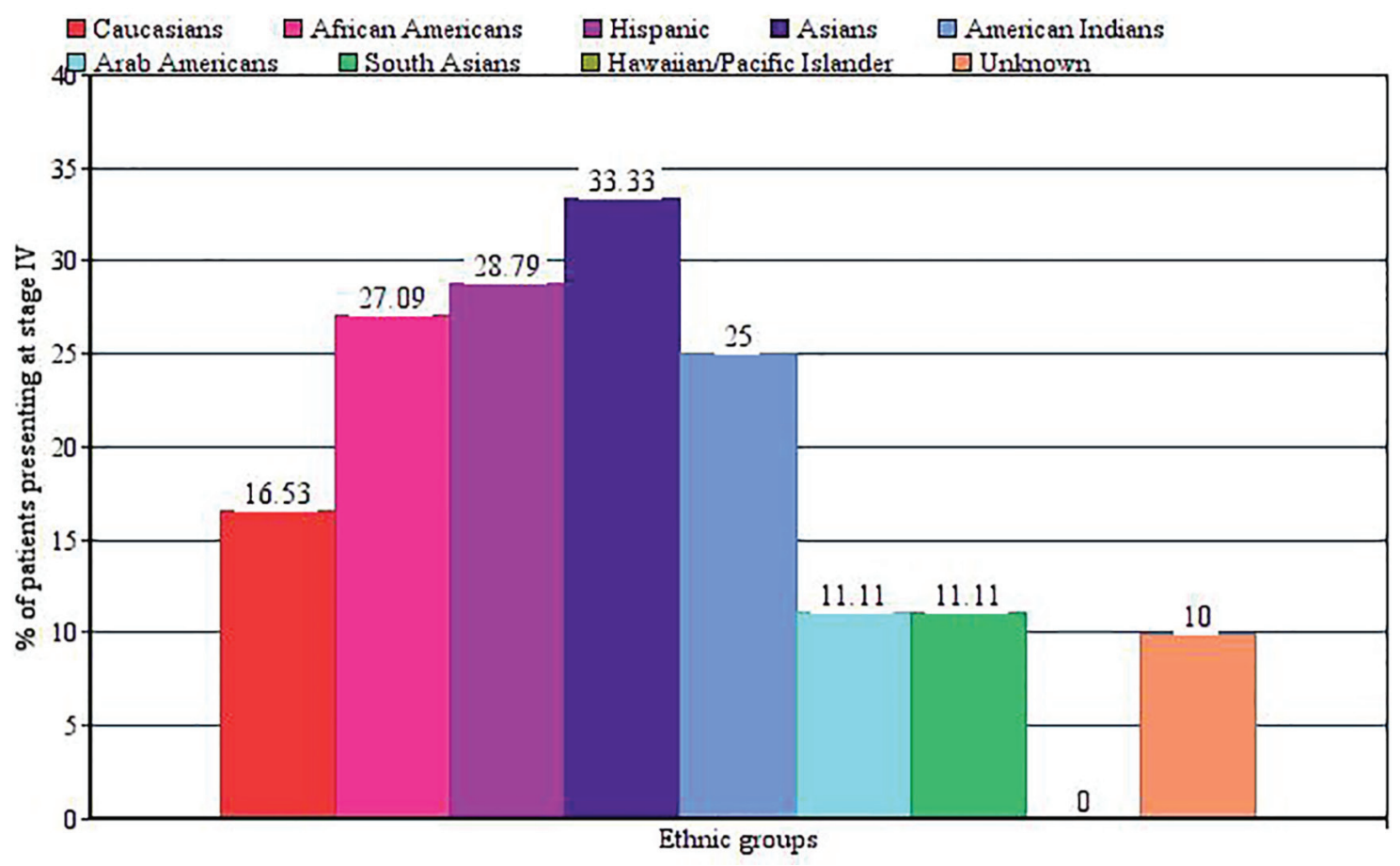

Figure 3. Bar graph showing ethnic variations of patients presenting with stage IV colorectal carcinoma on initial presentation.

\section{Site of CRC}

Rectum was the most common site of neoplasia (20.69\% of the total sample population) (Fig. 4). However, within the Asian racial group, we found that $30 \%$ had CRC in the sigmoid colon (14.14 \% in African Americans and $17.33 \%$ in Caucasians). Recto-sigmoid junction was another site of higher CRC incidence among Caucasians as compared to other races $(9.3 \%$ vs. $4.6 \%$ in African Americans).

\section{Type of CRC}

Adenocarcinoma remained the most common type of neoplasia among all racial groups (89.2\% of total) (Fig. 5). An important finding was higher incidence rate of carcinoid tumor among Hispanics as compared to other racial groups $(12.68 \%$ vs. $7.24 \%$ in African Americans and $3.1 \%$ in Caucasians).

\section{Survival times}

We observed racial disparities in terms of survival times among different racial groups. Our results indicated that African Americans have a worse survival probability over 5 years as compared to Caucasians. Results were statistically significant $(\mathrm{P}<0.0001)$ (Fig. 6).

Similarly, Hispanics had worse survival probability as compared to African Americans. Difference was especially more significant in early time period after initial diagnosis of CRC $(\mathrm{P}=0.031)$ (Fig. 7).
On further stratification of each racial group on gender basis, we noticed some interesting facts. Hispanic males showed a worse survival probability as compared to Hispanic females $(\mathrm{P}=0.04)$ (Fig. 8).

Similarly, African-American males tend to show worse survival probability as compared to females but results were not statistically significant $(\mathrm{P}=0.18)$. Caucasian males and females did not show any noticeable difference.

\section{Discussion}

$\mathrm{CRC}$ is one of the leading causes of cancer-related deaths in the United States. According to Center for Disease Control and Prevention, 51,516 people in the United States died from CRC, including 26,866 men and 24,650 women in 1 year [7]. It still remains as one of the biggest causes of mortality in West [8]. Racial disparities in survival have long existed [9-12]. Amri et al recently concluded that significant racial disparities for CRC persist despite low threshold for health care access in the US [13]. Studies have indicated highest incidence rates of CRC in African Americans [14]. Clear racial disparities were also noticed in CRC incidence rate, stage at diagnosis and survival times in Surveillance, Epidemiology and End Results (SEER) program data. Similar to other studies, incidence was highest in African Americans as compared to other racial groups and lowest for Asians $[15,16]$. This racial disparity could be attributed to numerous factors.

Although Caucasian and African American races have been well studied in past in terms of CRC, there is a general lack of research towards other races. Few studies have been 


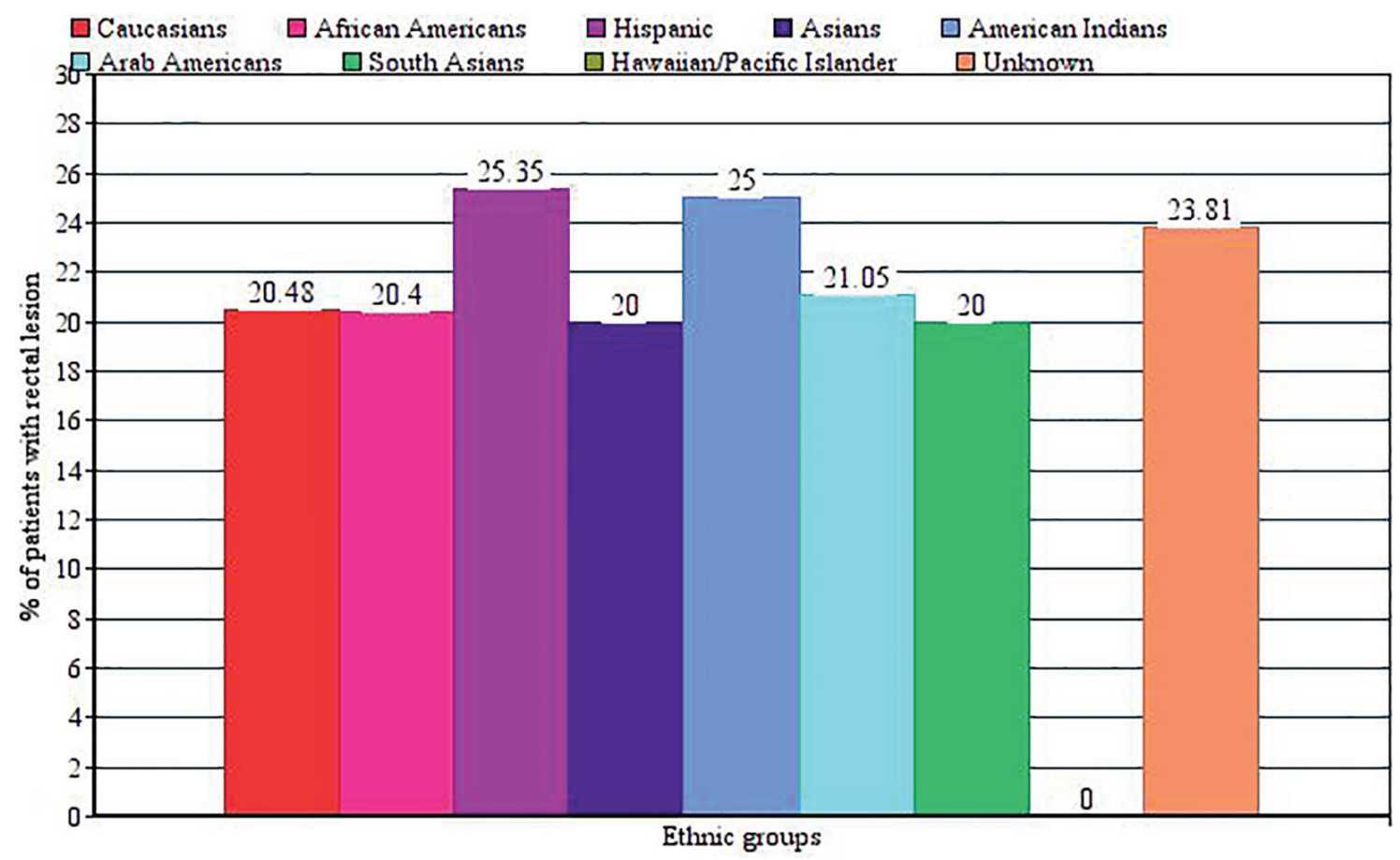

Figure 4. Bar graph showing ethnic variations of patients presenting with rectal carcinoma.

$\%$ of total patients presenting with adenocarcinoma

Caucasians

Arab Americans
African Americans

South Asians
Hispanic Asians

Hawaiian/Pacific Islander
American Indians

Unknown

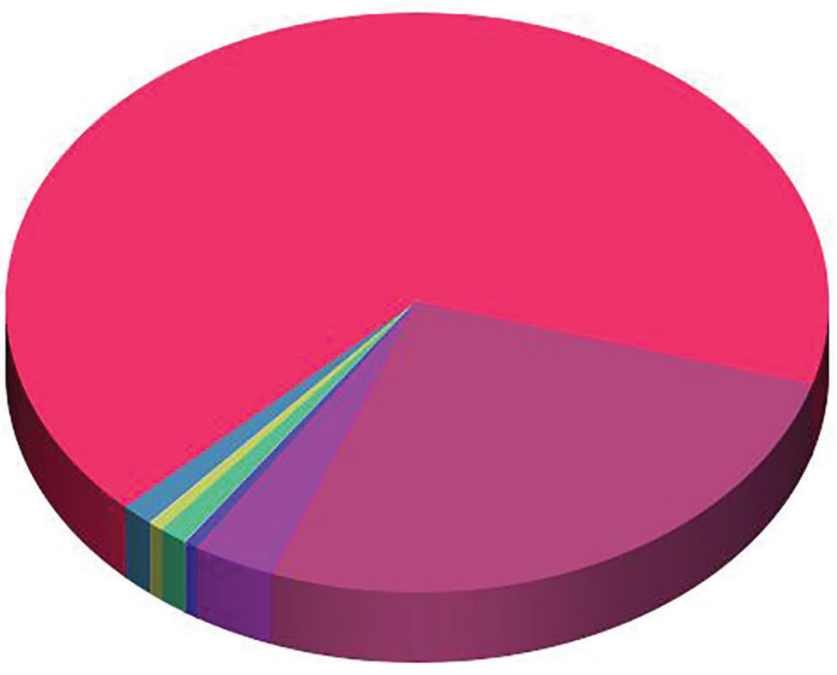

Figure 5. Pie chart showing different ethnicities presenting with colorectal adenocarcinoma. 


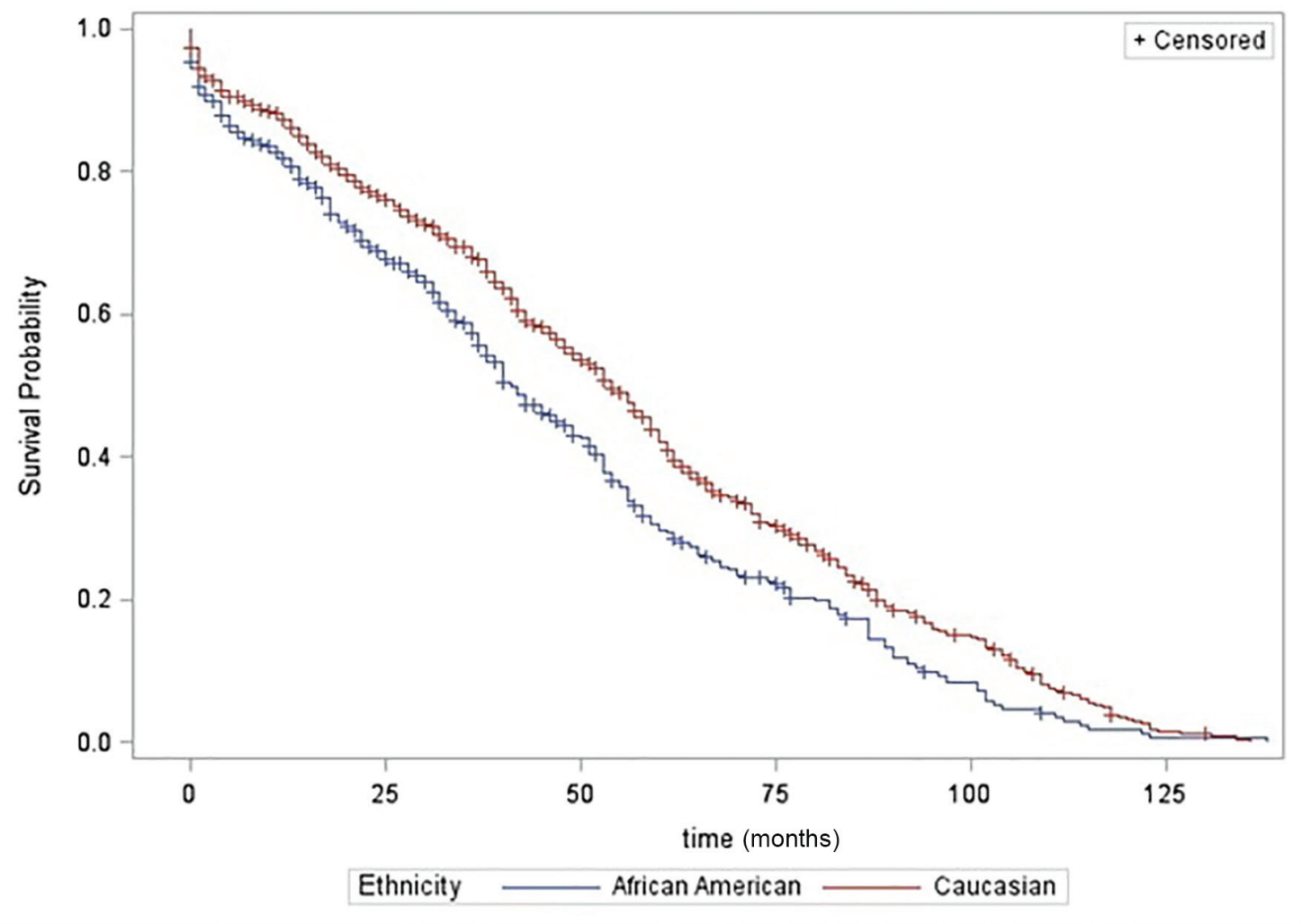

Figure 6. Comparison of survival time between African Americans and Caucasians.

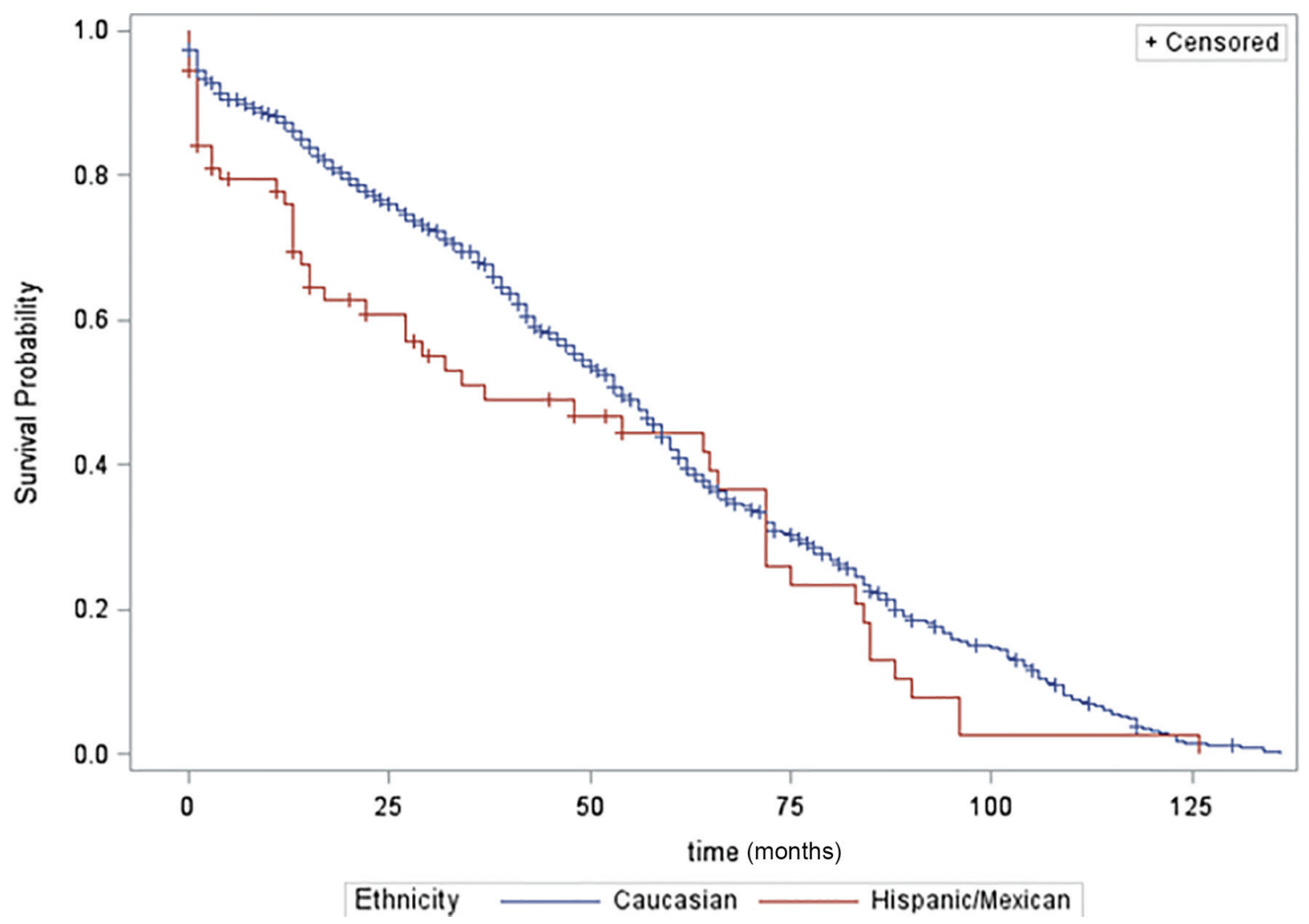

Figure 7. Comparison of Caucasians and Hispanics in terms of age at presentation. 


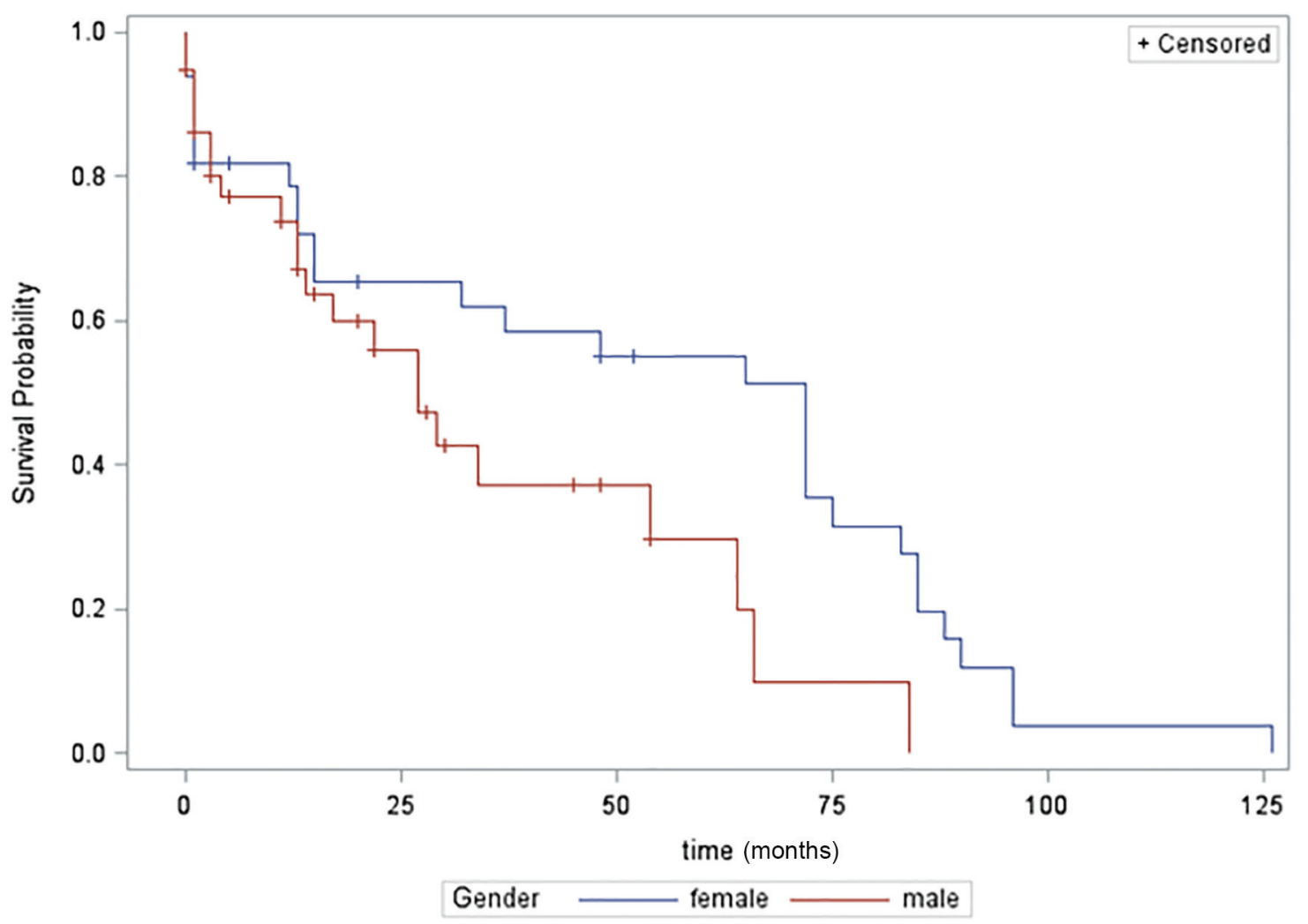

Figure 8. Comparison of Hispanic males and females survival probability over 5 years.

performed to study CRC in other racial groups [17]. Rahman et al studied racial disparities in CRC in patients $<50$ years of age. They found that significantly higher proportion of minority groups in USA with CRC are diagnosed before age $50 \mathrm{com}-$ pared to non-Hispanic Whites, indicating that these minority groups are at higher risk for early CRC [18].

As noted in our results section, mean age of presentation for CRC was approximately 60 years in Hispanics, 68 years in African Americans and 72 years in Caucasians. These results are similar to previous studies performed on this subject except the fact that African Americans were presenting at an earlier age. In a study performed by Chattar-Cora et al, mean age of presentation was 60.3 years in Hispanics, 63.5 years in African Americans and 71.7 years in Caucasians [19]. In another study, Hispanics were diagnosed at a median age of 57 years as compared to 67 years in Caucasians [20].

Histological stage of CRC was another important aspect of our study. Hispanics and African Americans presented predominantly at advanced stage of CRC as compared to other ethnicities. Study performed by Dr. Lai highlighted racial disparity of CRC and concluded that African Americans presented predominantly at advanced stages as compared to Caucasians [21]. Study performed on Florida Hispanics showed increasing trends of advanced stage CRC as compared to Caucasians. Other studies also showed similar trends [6,22].

Rectum was the most common site among all ethnic groups as noted above with most of the carcinomas found in distal bowel in our study. These results were in contrast to can- cer statistics published by Illinois Department of Public Health where CRC presented predominantly in proximal bowel (Caucasian: 54\%; African Americas: 51.3\%; Hispanics: 58.6\%) as compared to distal bowel (Caucasians: 46\%; African American: 48.7\%; Hispanic: 41.4\%) [23]. Another study performed by $\mathrm{Wu}$ et al showed that age-adjusted $\mathrm{CRC}$ incidence rates were significantly lower in Asians than in Caucasians and African Americans, particularly for proximal bowel neoplasia. Their study also showed significantly higher rectal cancer incidence rate in Asian males [24]. A distinct site of predominance cannot be clearly extracted from our present data for Hispanics, Asians, and Native Americans. A greater study population would be needed prior to making any conclusions.

Our study confirmed some notions and indicated some new interesting points in terms of survival probability over 5 years in different racial groups. It confirmed worse survival probability in African Americans and Hispanics as compared to Caucasians. Multiple studies in past have indicated worse outcomes in African Americans. Overall survival at 5 years after CRC diagnosis was $54.9 \%$ among African Americans, $68.1 \%$ among Caucasians, and $62.9 \%$ among Hispanics in one study [25]. Another study performed by Yan et al indicated similar results with high CRC-related mortality rates in African Americans as compared to Caucasians [26]. Silber et al found an absolute difference of $9.9 \%$ in 5 -year survival between African American and Caucasian patients [27]. Wallace et al demonstrated a higher risk of metachronous adenomas in African Americans compared with whites at younger ages 
[28]. There was a lack of data for direct comparisons in terms of CRC survival for Caucasians and Hispanics. Our results also highlighted interesting fact that Hispanic males show a worse survival probability when compared with Hispanic females.

Different factors can be attributed to observed differences in incidence and behavior of CRC among different ethnic groups. Lower CRC screening rate is one of the biggest factors contributing towards this discrepancy. Studies showed that minority ethnic groups have lower CRC screening rates [29-33]. This low screening rate becomes biggest contributor of higher CRC incidence in minority ethnic groups $[34,35]$. Studies in minority ethnic groups also indicated that fear of cancer is one of the causes of lower screening rates and there are misunderstandings regarding CRC screening [36-38].

Genetic differences are thought to be other important contributory factors for above mentioned racial disparity. Study performed by Carathers et al indicated microsatellite instability in African Americans as a significant contributory factor towards higher CRC-related mortality when compared with Caucasians [39]. Inra et al found an overall higher APC mutation rate in Asians, African Americans, and other groups as compared to Caucasians. However, this rate was similar in all groups when adjusted for polyp burden [40].

Socioeconomic status is another important factor contributing towards CRC-related morbidity and mortality. More socioeconomically deprived neighborhoods were found to have a higher CRC-specific risk of death in a study performed by Lian et al [41]. Few other studies showed similar results, highlighting role of socioeconomic status [42, 43].

Data also suggest that some racial groups residing in certain geographic regions had higher incidence and mortality rate from CRC $[44,45]$. These disparities in CRC highlighted significance of environmental factors.

Difference in treatment is also an important factor which should be kept in mind while considering racial disparities of CRC $[46,47]$.

We would like to acknowledge limitations in our study. An aggressive comparison of CRC amongst racial groups is limited due to unequal representation. The number of Hispanics, South Asians, Arabs, Asians and American Indians is significantly less than the number of Caucasians and African Americans. Though this is an accurate depiction of the population in the local area of the study, a statistically significant comparison was not possible. It may be possible that these population groups have limited resources and did not have access to standard healthcare or cultural norms prevent aggressive preventive measures and treatment. However, this study does show that increased awareness of the possibility of CRC presenting at a younger age in a more advanced stage amongst racial minorities is necessary. The limited data on racial minorities displayed in this study do show that such groups like Hispanics present at a younger and at advanced stage as compared to Caucasians and African Americans. Our study also does not take into account limiting socioeconomic factors that can contribute to these findings. It is vital to perform studies in minority racial groups taking into account genetic differences, socioeconomic status and geography. Such studies may be able to identify causes of variable disease presentation in different racial groups and lead to aggressive preventative measures that differ based on individual characteristics and predispositions.

\section{Conclusions}

In conclusion, CRC is a major cause of cancer-related mortality in the US. Individualized considerations for different racial groups are necessary on initial diagnosis of CRC as our study has highlighted some important differences in terms of survival probability, stage and location. Multicenter large studies are needed to further investigate disease behavior in minor racial groups.

\section{Author Contributions}

We certify that all authors contributed significantly to be listed as authors on this manuscript.

\section{Conflicts of Interest}

Authors certify that they do not have any conflicts of interest, financial or others, to disclose.

\section{References}

1. American Cancer Society. Cancer Facts \& Figures 2009. Atlanta: American Cancer Society; 2009.

2. Giovannucci E, Wu W. Cancers of the Colon and Rectum. In: Schottenfeld D, Fraumeni JF, editors. Cancer Epidemiology and Prevention. 3. New York, NY: Oxford University Press; 2006. p. 809-829.

3. World Cancer Research Fund / American Institute for Cancer Research Food, Nutrition, Physical Activity, and the Prevention of Cancer: a Global Perspective. AICR. 2007.

4. American Cancer Society. Colorectal Cancer Facts \& Figures 2014-2016. Available from http://www.cancer.org/ acs/groups/content/documents/document/acspc-042280. pdf. Atlanta: American Cancer Society, 2014.

5. Carethers JM. Screening for colorectal cancer in African Americans: determinants and rationale for an earlier age to commence screening. Dig Dis Sci. 2015;60(3):711721.

6. Doubeni CA, Field TS, Buist DS, Korner EJ, Bigelow C, Lamerato L, Herrinton L, et al. Racial differences in tumor stage and survival for colorectal cancer in an insured population. Cancer. 2007;109(3):612-620.

7. U.S. Cancer Statistics Working Group. United States Cancer Statistics: 1999-2012 Incidence and Mortality Web-based Report. Atlanta (GA): Department of Health and Human Services, Centers for Disease Control and Prevention, and National Cancer Institute; 2015.

8. Arvelo F, Sojo F, Cotte C. Biology of colorectal cancer. Ecancermedicalscience. 2015;9:520.

9. Albano JD, Ward E, Jemal A, Anderson R, Cokkinides 
VE, Murray T, Henley J, et al. Cancer mortality in the United States by education level and race. J Natl Cancer Inst. 2007;99(18):1384-1394.

10. Hashiguchi Y, Hase K, Ueno H, Shinto E, Naito Y, Kajiwara Y, Kuroda T, et al. Impact of race/ethnicity on prognosis in patients who underwent surgery for colon cancer: analysis for white, African, and East Asian Americans. Ann Surg Oncol. 2012;19(5):1517-1528.

11. Clegg LX, Li FP, Hankey BF, Chu K, Edwards BK. Cancer survival among US whites and minorities: a SEER (Surveillance, Epidemiology, and End Results) Program population-based study. Arch Intern Med. 2002;162(17):1985-1993.

12. Ward E, Jemal A, Cokkinides V, Singh GK, Cardinez C, Ghafoor A, Thun M. Cancer disparities by race/ethnicity and socioeconomic status. CA Cancer J Clin. 2004;54(2):78-93.

13. Amri R, Stronks K, Bordeianou LG, Sylla P, Berger DL. Gender and ethnic disparities in colon cancer presentation and outcomes in a US universal health care setting. J Surg Oncol. 2014;109(7):645-651.

14. Siegel R, Desantis C, Jemal A. Colorectal cancer statistics, 2014. CA Cancer J Clin. 2014;64(2):104-117.

15. Altekruse SF, Kosary CL, Krapcho M, Neyman N, Aminou R, Waldron W, Ruhl J, Howlader N, Tatalovich Z, Cho H, Mariotto A, Eisner MP, et al. SEER Cancer Statistics Review, 1975-2007. Bethesda, MD: National Cancer Institute; 2010.

16. Ries L, Eisner M, Kosary C, Hankey B, Miller B, Clegg LX. SEER Cancer Statistics Review, 1973-1999. Bethesda, MD: National Cancer Institute; 2002.

17. Rodriguez R, Gonzales M, Fahy B, Kinney A, Hoffman R, Rajput A. Disparities in Stage at Presentation and Treatment of Colorectal Cancer among Hispanic and NonHispanic White Patients. Am Surg. 2015;81(11):E353355.

18. Rahman R, Schmaltz C, Jackson CS, Simoes EJ, JacksonThompson J, Ibdah JA. Increased risk for colorectal cancer under age 50 in racial and ethnic minorities living in the United States. Cancer Med. 2015;4(12):1863-1870.

19. Chattar-Cora D, Onime GD, Valentine IS, Cudjoe E, Rivera L. Colorectal cancer in a multi-ethnic urban group: its anatomical and age profile. Int Surg. 2000;85(2):137142.

20. Katz M, Parrish ME, Li E, Zhang Y, Zhu W, Shroyer K, Bergamaschi R, et al. The Effect of Race/Ethnicity on the Age of Colon Cancer Diagnosis. J Health Dispar Res Pract. 2013;6(1):62-69.

21. Lai Y, Wang C, Civan JM, Palazzo JP, Ye Z, Hyslop T, Lin $\mathrm{J}$, et al. Effects of Cancer Stage and Treatment Differences on Racial Disparities in Survival From Colon Cancer: A United States Population-Based Study. Gastroenterology. 2016;150(5):1135-1146.

22. Cheng X, Chen VW, Steele B, Ruiz B, Fulton J, Liu L, Carozza SE, et al. Subsite-specific incidence rate and stage of disease in colorectal cancer by race, gender, and age group in the United States, 1992-1997. Cancer. 2001;92(10):2547-2554.

23. Garner K. Colorectal Cancer in Illinois: An Overview of Key Statistics. Epidemiologic Report Series 11:04. Springfield, Ill.: Illinois Department of Public Health, June 2011.

24. Wu X, Chen VW, Martin J, Roffers S, Groves FD, Correa $\mathrm{CN}$, Hamilton-Byrd E, et al. Subsite-specific colorectal cancer incidence rates and stage distributions among Asians and Pacific Islanders in the United States, 1995 to 1999. Cancer Epidemiol Biomarkers Prev. 2004;13(7):1215-1222.

25. Holowatyj AN, Ruterbusch JJ, Rozek LS, Cote ML, Stoffel EM. Racial/Ethnic Disparities in Survival Among Patients With Young-Onset Colorectal Cancer. J Clin Oncol. 2016;34(18):2148-2156.

26. Yan B, Noone AM, Yee C, Banerjee M, Schwartz K, Simon MS. Racial differences in colorectal cancer survival in the Detroit Metropolitan Area. Cancer. 2009;115(16):37913800 .

27. Silber JH, Rosenbaum PR, Ross RN, Niknam BA, Ludwig JM, Wang W, Clark AS, et al. Racial disparities in colon cancer survival: a matched cohort study. Ann Intern Med. 2014;161(12):845-854.

28. Wallace K, Burke CA, Ahnen DJ, Barry EL, Bresalier RS, Saibil F, Baron JA. The association of age and race and the risk of large bowel polyps. Cancer Epidemiol Biomarkers Prev. 2015;24(2):448-453.

29. Perez-Stable EJ, Otero-Sabogal R, Sabogal F, McPhee SJ, Hiatt RA. Self-reported use of cancer screening tests among Latinos and Anglos in a prepaid health plan. Arch Intern Med. 1994;154(10):1073-1081.

30. Perez-Stable EJ, Sabogal F, Otero-Sabogal R. Use of cancer-screening tests in the San Francisco Bay area: comparison of Latinos and Anglos. J Natl Cancer Inst Monogr. 1995;18:147-153.

31. Harlan LC, Bernstein AB, Kessler LG. Cervical cancer screening: who is not screened and why? Am J Public Health. 1991;81(7):885-890.

32. Cooper GS, Koroukian SM. Racial disparities in the use of and indications for colorectal procedures in Medicare beneficiaries. Cancer. 2004;100(2):418-424.

33. Schenck AP, Klabunde CN, Davis WW. Racial differences in colorectal cancer test use by Medicare consumers. Am J Prev Med. 2006;30(4):320-326.

34. Hernandez MN, Sussman DA, Lee DJ, Mackinnon JA, Fleming LE. Trends in colorectal cancer among hispanics by stage and subsite location: 1989-2006. Clin Transl Gastroenterol. 2012;3:e21.

35. Walsh JM, Kaplan CP, Nguyen B, Gildengorin G, McPhee SJ, Perez-Stable EJ. Barriers to colorectal cancer screening in Latino and Vietnamese Americans. Compared with non-Latino white Americans. J Gen Intern Med. 2004;19(2):156-166.

36. Lantz PM, Dupuis L, Reding D, Krauska M, Lappe K. Peer discussions of cancer among Hispanic migrant farm workers. Public Health Rep. 1994;109(4):512-520.

37. Keefe S. Acculturation and the extended family among urban Mexican-Americans. In: Padilla AM, editor. Acculturation Theory Models and Some New Findings. Boulder, Colo: Westview Press; 1980.

38. Carpenter V, Colwell B. Cancer knowledge, self-efficacy, 
and cancer screening behaviors among Mexican-American women. J Cancer Educ. 1995;10(4):217-222.

39. Carethers JM, Murali B, Yang B, Doctolero RT, Tajima A, Basa R, Smith EJ, et al. Influence of race on microsatellite instability and CD8+ T cell infiltration in colon cancer. PLoS One. 2014;9(6):e100461.

40. Inra JA, Steyerberg EW, Grover S, McFarland A, Syngal $\mathrm{S}$, Kastrinos F. Racial variation in frequency and phenotypes of APC and MUTYH mutations in 6,169 individuals undergoing genetic testing. Genet Med. 2015;17(10):815821.

41. Lian M, Schootman M, Doubeni CA, Park Y, Major JM, Stone RA, Laiyemo AO, et al. Geographic variation in colorectal cancer survival and the role of small-area socioeconomic deprivation: a multilevel survival analysis of the NIH-AARP Diet and Health Study Cohort. Am J Epidemiol. 2011;174(7):828-838.

42. Marcella S, Miller JE. Racial differences in colorectal cancer mortality. The importance of stage and socioeconomic status. J Clin Epidemiol. 2001;54(4):359-366.

43. Haas JS, Earle CC, Orav JE, Brawarsky P, Neville BA, Williams DR. Racial segregation and disparities in cancer stage for seniors. J Gen Intern Med. 2008;23(5):699-705.

44. Flood DM, Weiss NS, Cook LS, Emerson JC, Schwartz SM, Potter JD. Colorectal cancer incidence in Asian migrants to the United States and their descendants. Cancer Causes Control. 2000;11(5):403-411.

45. American Cancer Society. Hawaii cancer facts \& figures 2003-2004. Honolulu: 2003.

46. Govindarajan R, Shah RV, Erkman LG, Hutchins LF. Racial differences in the outcome of patients with colorectal carcinoma. Cancer. 2003;97(2):493-498.

47. Baldwin LM, Dobie SA, Billingsley K, Cai Y, Wright GE, Dominitz JA, Barlow W, et al. Explaining black-white differences in receipt of recommended colon cancer treatment. J Natl Cancer Inst. 2005;97(16):1211-1220. 